\title{
Gaining perspective: Peer mentors' experiences with an intervention project for mothers with postpartum depression
}

\author{
Joni Leger ${ }^{* 1}$, Nicole Letourneau ${ }^{2}$, Kathryn Weaver $^{3}$ \\ ${ }^{1}$ School of Graduate Studies, University of New Brunswick, Fredericton, New Brunswick, Canada \\ ${ }^{2}$ Parent-Infant Mental Health, Faculty of Nursing, University of Calgary, Calgary, Alberta, Canada \\ ${ }^{3}$ Faculty of Nursing, University of New Brunswick, Fredericton, New Brunswick, Canada
}

Received: August 4, 2014

DOI: $10.5430 /$ cns.v3n1p29
Accepted: October 15, $2014 \quad$ Online Published: November 12, 2014

URL: http://dx.doi.org/10.5430/cns.v3n1p29

\begin{abstract}
This study explored the experiences of peer mentor volunteers who participated in an intervention project, Mothers Offering Mentorship and Support (MOMS), for new mothers with postpartum depression (PPD). A descriptive phenomenological approach was used to capture the meaning and common features of their experiences. Six of the peer mentors who participated in the MOMS study participated in the current study. Overall, the peer mentors had a positive experience. They felt helpful and derived satisfaction from providing support to other mothers. The general structure of the peer mentoring experience was one of gaining perspective. Gaining perspective included themes of structuring a common connection, perceived impact on moms and mentors, understanding challenges, and informing future peer mentor programs. Both peer mentors and moms saw the benefit of having PPD support, however, some of the moms had needs that exceeded the scope of the peer mentors' roles highlighting the need for access to additional resources.
\end{abstract}

Key Words: Postpartum depression, Maternal mental health, Peer support

\section{Introduction}

Postpartum depression (PPD) has been identified as a serious and pervasive mental health issue with potentially harmful long term consequences for both the affected mother and her family. ${ }^{[1-3]}$ One approach to PPD intervention is peer mentoring where a woman who has experienced and recovered from PPD and is perceived as an equal, not a professional, provides guidance and support through shared experience with a mother who is currently experiencing PPD. ${ }^{[4]}$ Peer mentors provide information, feedback and emotional support based on their personal experience. ${ }^{[5]}$

Peer mentoring has been used as a health intervention with diverse groups to mitigate the feelings of isolation that often accompany a state of ill-health, ${ }^{[6]}$ or recovery from illhealth, ${ }^{[7]}$ and to provide support for those facing a significant life change. ${ }^{[8]}$ Studies have also examined the effects of peer mentoring to improve maternal and child health outcomes, ${ }^{[9]}$ to encourage breastfeeding, ${ }^{[10]}$ to support the development of parenting skills ${ }^{[11]}$ and to provide support to women coping with PPD. ${ }^{[5,12]}$ Peer mentors can offer their mentees the opportunity to validate feelings and attitudes through intimate peer-oriented exchanges. One of the most important characteristics of peer support providers cited by those receiving support is their knowledge based on having "been there" themselves. ${ }^{[6,8]}$ Evidence supports the no-

*Correspondence: Joni Leger; Email: jleger.home@gmail.com; Address: 24 Glenview Court, Riverview, New Brunswick, E1B 4X7, Canada. 
tion that peer mentoring is an effective method of providing support to new mothers with PPD. ${ }^{[5,13]}$ Women themselves have identified their preference for receiving support from someone who understands or who has experienced PPD. ${ }^{[14,15]}$ A qualitative systematic review of PPD treatment preferences found that support from other mothers was perceived as important to recovery from PPD. ${ }^{[16]}$ Studies looking at social support for PPD provide further evidence for its benefits and women's desire to access social support. ${ }^{[17-19]}$

The purpose of this study was to better understand the experiences of peer mentor volunteers who participated in the Mothers Offering Mentorship and Support (MOMS) study, ${ }^{[20]}$ a multi-site randomized controlled trial (RCT) investigating the impact of home-based peer support on maternal-infant interactions, maternal mental health, and infant health outcomes. In the MOMS RCT, women with depressive symptomatology were recruited and randomly allocated to either the intervention or control group conditions. The intervention consisted of volunteer peer mentors providing support via in-home weekly visits for approximately 12 weeks. Peer support consisted of emotional (e.g. listening), affirmational (e.g. reassurance), instrumental (e.g. help with infant care) and informational (e.g. advice and guidance) support. Informational support was provided to fill knowledge and resource gaps about PPD and to provide information and role modeling to promote optimal maternal-infant relationships (see Letourneau et al. ${ }^{[20]}$ for detailed description of the peer-support intervention). Visits typically lasted from an hour to an hour and a half. The fewest number of weeks a mentor visited with a mentee was three and most of the mentors visited their mentees between nine and twelve weeks. For the purpose of offering informational support, all of the mentors were asked and did attempt to deliver the Keys to Caregiving (KTC) parenting education program. The KTC is a tool intended to teach about the competencies and capabilities of the newborn and their effect on caregiver-infant interaction it includes instructional pamphlets on infant state, infant behavior, infant cues, state modulation and feeding interaction. The goal of the MOMS study was to evaluate the impact of support on maternal outcomes. The current study sought to understand peer support from the perspective of the peer mentors.

\section{Methods}

A descriptive phenomenological research design was used to explore the experiences of PPD peer mentors and to describe the meaning and common features of their experiences. ${ }^{[21,22]}$ Ethics approval was obtained from the University of New Brunswick Research Ethics Board.

\subsection{Data collection}

Twelve peer mentor volunteers who participated in the original MOMS study were invited to participate in the cur- rent study. The only criterion for inclusion in the current study was that they had participated as peer mentors with the MOMS study. Six accepted the invitation to participate and were interviewed individually either by telephone or in person. Those that declined were not asked for a reason for not participating nor did they offer one. Six participants is adequate to achieve the goals of this particular study as sample sizes in phenomenological studies rely more on the goals and purpose of the study with typical sample sizes ranging from 1-10 participants. $^{[22]}$

The primary investigator conducted interviews with each of the six participants. The interviews followed a semistructured format with five open-ended questions regarding their experience: (1) Can you describe for me your experience of peer mentoring women with PPD? (2) What were the challenges of your peer mentoring experience? (3) What were the benefits of your peer mentoring experience? (4) What do you think your experience can contribute to improving peer mentoring support programs for women with PPD? and (5) Is there anything else that you would like to share regarding your experience as a peer mentor? Follow-up probes were asked to help clarify or elaborate on something they said such as, "Could you tell me more about what you just said about how it would help you to move forward?"

The six interviews lasted between 45 minutes and 90 minutes each, were audio-recorded and then transcribed. Throughout the article the terms "mom" or "moms" refer specifically to the mothers who received support in the original MOMS study.

\subsection{Data interpretation}

The transcribed audio-recordings underwent a phenomenological analysis by the primary investigator based on Giorgi's $^{[21]}$ interpretation of the basic steps of qualitative inquiry. In the first step the data were collected and transcribed by the primary investigator who kept a reflexive journal for bracketing thoughts on the peer mentors' experiences. Bracketing is a means of putting assumptions into abeyance ${ }^{[23]}$ or clearing the mind of previous experience to deliberately examine the researcher's own beliefs and assumptions. ${ }^{[24]}$ The reflexive journal was used to keep separate the primary investigator's thoughts about her experience as a peer mentor from the experiences of the women she interviewed. By clarifying her own experience she was able to listen more openly to the experiences of the others and not make assumptions about how each of them experienced peer mentoring.

In the second step each transcript was read through in its entirety to get a sense of the participant's experience as a whole and returned to as necessary to provide context during each subsequent step. The third step consisted of reading through each transcript again more purposefully and break- 
ing the text into segments, or meaning units, of phrases or sentences where there is a shift in meaning or a change in intention or perspective. According to Giorgi, ${ }^{[25]}$ meaning units are identified by the researcher through an intuitive and spontaneous awareness of a transition in meaning, they can vary in length, and there is no set criteria upon which they are dependent.

In step four, the meaning units were examined and the process of imaginative variation was used to draw out their essential meaning. In imaginative variation the researcher explores the various possibilities that a meaning unit can hold, moving back and forth between the possible and the given to arrive at the essential meaning. Once the essential meaning was discovered these units then informed a situated structure where meaning units were combined into larger units when it was clear they contributed to a single theme. In the final step, the patterns and common features of the mentors' experiences informed a general structure for the phenomenon of interest - peer mentoring women with PPD. The general structure of the peer mentoring experience was gaining perspective.

\section{Results}

The mentors spoke of their overall experience providing support to moms as a positive one, feeling that it was rewarding and they gained something from it. There was satisfaction derived from being able to provide for someone else the support and understanding that the mentors had missed in their own PPD experience. They felt they made a difference for the women they mentored, experienced growth in their own healing, and gained perspective on the whole PPD experience. One mentor, M2, described the experience as "almost like a healing process", she felt she was "able to label, identify and normalize" what she had gone through in dealing with her own PPD. Overall, gaining perspective entailed themes of structuring a common connection, perceived impact on moms and mentors, understanding challenges, and informing future peer mentor programs.

\subsection{Structuring a common connection}

All visits began with the mentor establishing contact with the mom after which they agreed to meet regularly. The mentors sought common connection with the moms through sharing their own experiences and supporting the moms in theirs. Structuring a common connection involved establishing contact, finding common ground, being supportive, drawing on PPD experience, enhancing mother-infant interaction, and supporting medication decisions.

The mentors experienced only minor difficulties establishing contact and meeting times with the moms. Moms who were contacted were receptive to hearing from the mentors and welcoming when they visited. The mentors' commitments and responsibilities, such as their children, their

Published by Sciedu Press work, and their home responsibilities all played a role when arranging times to meet and the amount of time they had to commit to mentoring. Geographical proximity facilitated visitation through limiting the total amount of time required for the mentors to make the visits and through the shared experience that comes from living in the same area. Keeping the same meeting time each week worked well for most mentors and moms, "Monday would be the day I would visit and then it was expected. I would call to confirm and there was never a problem."(M5)

During the first few visits mentors worked to build rapport with their moms through shared experience of the transition to motherhood. A common topic was mom's life before becoming a mother. In one case a peer mentor and mom even discovered they had attended the same dance school giving them an additional means of connecting with each other. The mentoring relationships followed a natural progression of developing trust to achieve a comfort level where the moms felt they could ask freely about the mentor's personal experience. One mentor shared, "They would... ask questions... did you feel this, or what did you do if you felt that, or did you ever feel like this?" (M3) Instrumental support such as changing diapers, bathing baby, holding baby, or helping mom clean the house or do dishes helped build connection too. The mentors felt it was important to support the moms in whatever way they could though some of the moms did not seem to know what they needed: "There were times... where I don't feel like she knew what she needed and so, just to be there and sit in her kitchen with her and have a cup of tea and talk about even the weather or whatever, just to have someone there, I think is a good thing." (M1)

While some of the mentors did not feel comfortable giving advice, "I didn't really offer any advice because that [giving advice] is not my area of expertise" (M4), they did try to reduce the moms' anxiety through helping the moms regain perspective: “I wasn't giving advice or anything, it's just I was able to ... kind of bring things down and give perspective ... I can think of one mom in particular ... she was quite grateful for that because she had someone, a touchstone, somebody to check in with about things."(M1)

The mentors drew heavily from their own experience to provide support and felt good about being able to use their experience to help someone else. They felt that personal experience with PPD provided them with experiential knowledge and helped them be more empathetic towards the moms. Moreover, the experience of mentoring helped them gain perspective and a better understanding of what they had been through themselves. The mentors felt that moms were asking about their PPD experiences to normalize their own feelings and to know they were not alone in how they were feeling "My experience ... she liked to hear, she wanted to hear about that, and what stuff was normal." (M3) Overall, the mentors felt their experience with PPD helped them re- 
late to what the moms were going through and to connect with them. One mentor did experience difficulty relating to a mom because their PPD experiences were so different from one another. Yet, despite this perceived lack of connection, the mom verbally expressed her appreciation for the mentor's support, "The comments that I received, she always thanked me when I was leaving, so it just seemed that she was grateful for the support." (M1)

Mentors delivered the KTC program and endeavored to help moms interact with their infants. Mentors observed that moms became more comfortable with their parenting role over time and were more engaged with their baby by the end of the mentoring visits. However, mentors felt that infant growth played a more significant role in the changes in mother-infant interactions than the KTC informational support.

The mentors and moms found common ground when sharing their experiences with decision making around medication to help cope with PPD. Some of the moms taking medication conveyed displeasure with doing so, expressing a lack of awareness or availability of other options. Whether they had taken medication or not, the mentors felt able to provide support because they had been faced with the same decision in their own PPD experience. Both mentors and moms talked about the stigma they associated with taking medication. Some felt that taking medication may be perceived by other people as a sign of weakness or an inability to cope with new motherhood. Some moms also expressed a concern about developing a dependency. A couple of the moms wanted to work through their PPD without medication and sought out other resources. One mentor felt that the peer mentoring program was certainly one of these resources "She (mom)... was really feeling that she had some tools and some strategies now to help her get through this .. I I was one of those things that she had." (M6)

Both moms and mentors talked about being on medication at the recommendation of their physician. Some experienced adverse side effects and some could not afford medication while others had a positive experience and felt the medication was a good choice for them. Overall, how a mom felt about taking the medication, whether she perceived it as a positive or a negative, is what really mattered "As long as she felt good about it that was the main thing." (M1)

\subsection{Perceived impact on moms and mentors}

Some mentors felt uncertain regarding their impact. They thought they had an impact but did not know for certain whether they did. As one mentor stated "I hope so. I mean, I feel I did... do I know I did? No. But I do feel I did." (M6) While another mentor, M3, expressed "I hope, even if it was to educate them a little bit, I hope so, but as far as the whole getting through the postpartum, I'm not sure." Others were more confident regarding their impact "I felt that I was making a difference to these women." (M1) M5 felt that "at a minimum ... I had an impact, at maximum ... I'd like to think that the mom was feeling a lot better at the end." The feedback from the moms to the mentors indicated they did have an impact. One mom shared that she was "quite grateful ... to have had somebody to check in with about things." (M1)

Mentors witnessed positive changes in moms' moods and behaviors such as seeking out additional supports, becoming happier and more talkative by the end of the visiting, exhibiting greater pride, taking more initiative, and no longer crying at every visit. One mentor was particularly pleased with mom's growth “she was planning work and planning to do things and just being more active... she was coping better... she was planning to do things with her life to improve her situation.” (M5)

Mentors felt they learned from this experience gaining new skills, perspective on their own PPD experience, and about providing support for other women with PPD. One mentor summed up the impact for her: "The fact that I have any knowledge to give to anybody is quite amazing because five years ago I was where this lady was, just, you know, crying on the couch wishing your life wasn't this ... so it was neat to see that growth and to be able to give that hope back to someone and be like, yeah, you know what, it'll be okay." (M6)

They felt their abilities to be compassionate and empathetic had improved. Some felt they gained a better understanding of infant cues and states through the KTC. One mentor reflected "I think in a lot of ways it helped me realize how far I've come as mom." (M6) One mentor learned that women's experiences with PPD can be very different and felt this may indicate a difference in their support needs. Some women may not recognize when they need help or where to go once they do. Mentors felt that having access to support, such as peer mentoring, could help moms before things get out of control: "Any mom that comes in and that shows even little signs... she shouldn't have to be suicidal to get someone in to talk to her... she shouldn't have to want to hurt her baby, and she shouldn't have to, never laugh, always cry, like that checklist. You have to be so far over one side for anybody to notice... I think ... even if you're sometimes depressed and you're sometimes feeling like this sucks, someone should be offered to you to come and talk to you." (M6) While it was, at times, difficult to watch the moms go through familiar struggles; the mentors felt they were far enough removed from their own PPD experiences to be helpful and that it was, indeed, important that moms received support from someone who understood what they were going through.

\subsection{Understanding challenges}

Mentors gained perspective on the difficulties that can arise when trying to provide peer mentor support. Challenges identified by the peer mentors were establishing contact, 
bridging geographical distance, building trust, limited resources, accepting the moms' parenting choices, and implementing the parent education program. While mentors felt able to cope with most of these challenges they felt some were beyond the scope of their skills and resources.

Establishing contact and arranging visits went well in most cases. One mentor was met with attempts by her moms to cancel their visits. The mentor was persistent with these moms feeling that their attempts to cancel were not a reflection of their desire for support and through her persistence she was able to establish a positive peer support relationship with them.

The distance the mentors had to travel to see their moms was a challenge for some of the mentors though one was willing and able to travel a great distance to fulfill her mentoring commitment "I actually drove two hours to see her each way every week for twelve weeks." (M5) Some mentors found their own schedules challenging and wished they had more time to commit.

Building trust was not always easy. Personality differences posed some challenges and reinforced the need for mentors and moms to be well matched. One mentor felt there may have been some uncertainty on the part of the moms she worked with regarding her role and how much they could share with her "I tried to make my role very clear, like, I'm just here to help and not judge." (M3)

Mentors found it difficult to accept the things that were beyond their control such as lack of access to additional resources, lack of childcare, lack of support moms received from their partners, and lack of support for the couple. Mentors expressed frustration at not being able to access or provide more help for the moms as some of the moms had needs that went beyond the scope of the peer mentor's role and that they simply could not address. Some moms had other health issues they were dealing with (e.g. an eating disorder, a physical disability). Some were experiencing marital issues (e.g. lack of partner support, unstable marriage) or family of origin issues (e.g. a substance abusing parent) Mentors noted that these issues that were already part of the moms' lives continued to exist after the baby arrived and were amplified by the inability to cope that often accompanies PPD.

Mentors felt a lack of childcare affected the ability to relax and talk freely "Not that children should be a challenge ... I just felt for her that we just couldn't sit in private and just talk or anything." (M4) One mentor who attempted to access help from other resources felt frustrated because "when you tried to get help for her with other resources like through public health ... she didn't fit any criteria." (M5) Some mentors found it challenging to accept the parenting choices of their moms. In addition to providing PPD support one mentor felt obligated to try to teach mom additional life skills "I tried to talk to her about the importance

Published by Sciedu Press of a clean and safe ... environment for babies." (M5) The mentor struggled to relate to this mom's situation because the mentor had never encountered the realties faced by this mom who lived in socioeconomic disadvantage. The mentor felt it was imperative that this mom receive additional support and sought it out for her. The mentor in this situation shared that she "certainly felt ... a bit helpless." (M5)

Interestingly, the KTC parenting education program served as a barrier to seeking common ground in that the peer mentors felt the teaching role created a power imbalance. While the mentors felt that the KTC were helpful for some of the moms others were simply not receptive. Some mentors were uncomfortable delivering the KTC and felt that it was almost condescending to the moms. Overall, mentors felt some discomfort going in as a peer mentor trying to teach about parenting when peer mentors are supposed to be viewed as equals with the moms they are supporting. Some only delivered the KTC because they were obligated to though they acknowledged that the KTC did facilitate the initiation of conversation. Mentors did not feel comfortable with the educational aspect of their mentoring role "I felt like I was of more use in a support role rather than an educational role." (M1) Mentors felt the role of educating may be better left to professionals.

\subsection{Informing future peer mentor programs}

Mentors shared that future peer mentors need to go in knowing that they are there to support the mom in whatever way she needs which may include helping with laundry, holding the baby, talking about their own experience, or going for a walk. The most helpful thing one mentor wanted to share from her experience is for mentors to "go in without an agenda" (M1). Overall, the mentors did whatever they could to help the moms cope even though they knew they couldn't fix everything for them, "I wished I could have waved a wand and made all of those problems go away but you couldn't ... you could really just help the moms cope." (M5)

Although not all moms will have the same level of interest in it, the mentors felt it may be helpful to have more information and support available including literature, a web resource, or a telephone hotline. They suggested there could be more materials for mentors to leave with the moms or a list of books available at the library or other material that a peer support program could loan to moms.

All of the mentors felt there needed to be increased awareness among health care professionals about PPD because although moms can talk to their doctors or other health care providers about it, many may not chose to: "You can go to your doctor and talk about these things too, but whether or not some actually do that's the other thing. So, you know, just having information say at health centers as you're going to get immunizations for your kids, libraries, you know, all sorts of different places, just where you can kind of take 
a glance and it's like, that's some information that I'd like to read about." (M4)

While the role of peer mentors does involve some informal teaching, the mentors felt something as structured as the KTC may be better left to professionals. Mentors felt that it is important that moms are connected with other supports and services in addition to a peer mentor since peer mentors are not intended to be, nor can they take the place of, professionals. If a peer mentor encounters issues beyond her scope of support it would be beneficial if she were able to refer that mom to the appropriate professional.

Mentors felt that future peer mentoring programs should include screening at the outset to identify factors in the mom's family and social network that may need to be addressed. Screening should be followed by linking the mom with a well matched peer mentor. The amount of support required would be determined based on the preferences and needs of the mom with consideration given to the needs of her family. All of the mentors would recommend peer support for other moms and would volunteer to provide peer support again.

\section{Discussion}

The purpose of this study was to gain a better understanding of PPD peer support through the first-hand perspective of peer mentors. All of the mentors interviewed found the experience rewarding and valuable. Other studies have reported similar findings regarding positive outcomes for peer volunteers. ${ }^{[5,13]}$ In Fogarty and Kingswell's ${ }^{[13]}$ study, volunteers reported a sense of achievement and personal growth, a sense of personal benefit from the training, and increased personal skills. In addition to being rewarding, the mentors in the current study felt they gained new perspective on their own PPD experiences and learned about what is needed when providing support for another woman experiencing PPD.

Some mentors indicated there was an element of healing for them. Perhaps this stemmed from providing the support they had longed for in their own PPD experience or from learning more about what they went through, albeit at a safe distance from the experience. As was found in another study looking at social support for PPD ${ }^{[26]}$ both the peer mentors and the moms sought to normalize their symptoms through connecting with others.

Mentors felt their experiential knowledge contributed to their ability to provide empathetic support. They felt that discussing their personal experiences helped the moms normalize what they were going through. Consistent with previous research on mothers' perceived support needs during PPD ${ }^{[15]}$ mentors felt that support from another experienced mother would have been beneficial to them when they were in need.

Volunteer availability and commitment can be influenced by volunteers having their own family, employment, or other volunteer commitments. It may be helpful to try and ensure close proximity to moms to reduce travel times for peer mentors. Living in the same locale can also provide common ground for conversation and connection. Recognizing the importance of commonalities for creating connection, previous researchers have made efforts to ensure that matching occurs between volunteers and the women they support. ${ }^{[9,13,27]}$ Childcare was identified as another potential barrier to providing support. It may be worthwhile for future PPD support programs to consider making arrangements to provide temporary childcare for one or two visits to give moms a chance to speak freely with their mentors. Alternatively, telephone-based support would remove barriers such as the amount of time commitment required from volunteers, travel distance, transportation, and childcare. ${ }^{[28]} \mathrm{Fu}-$ ture research could look at using technology such as Skype or Face Time to facilitate peer mentor support. Similar to telephone support, these technologies help overcome some of the barriers to providing support. It would be worthwhile investigating whether the added visual connection makes any difference to the support provided.

There were some issues with the parenting education program not being received well by the moms and the peer mentors not being comfortable delivering it. Peer mentors felt more comfortable in their role as support providers rather than educators. Indeed, support providers in Fogarty and Kingswell's ${ }^{[13]}$ study were hesitant when asked about expanding their roles to include a larger educational component indicating some discomfort with providing education in lieu of support. The peer mentors in the current study felt that an educational component may be better received if delivered by a professional who is perceived as an educator.

Some of the mentors did not feel entirely certain of the impact they had while others were quite confident their support made a difference. While this may simply reflect individual differences between mentors, it may be worthwhile for future peer support programs to include some type of evaluation that could be used to provide feedback to volunteers. Both mentors and moms saw the benefit of being able to access PPD support, however, some of the moms had needs that exceeded the scope of the peer mentors' roles highlighting the need for access to additional resources. A team approach to supporting mothers with PPD that enables mentors to refer moms to appropriate health and social service providers as needed would address this. Future research that specifically uses a team approach to providing support to new mothers with PPD would help clarify the significance and utility of various professional and paraprofessional roles.

\section{Conclusion}

The women who volunteered to be peer mentors felt that they could help other moms. They were not afraid to share their stories or deal with memories of their own PPD ex- 
periences if it meant someone else would suffer less than they did. Peer mentoring was a positive experience for both those receiving support and those providing the support. Peer mentors gained perspective on their own experience and learned about providing support to others while, in turn, the moms had someone who listened to them and offered support and understanding. It is hoped that understanding these peer mentors' experiences will help with planning and implementing future peer mentoring support for PPD. With technology advancing the way it is future researchers may want to explore how best to use such technologies in providing support and with the growth of interdisciplinary ap- proaches to health care, future research should also look more closely at what type of team approach to PPD would be most beneficial.

\section{Acknowledgements}

We would like to thank the women who volunteered as peer mentors and who participated in this study, without their commitment this would not have been possible. The data collection and analysis in this article were funded by the Canadian Institutes of Health Research Canada Graduate Master's Award.

\section{References}

[1] Beck CT. Maternal depression and child behavior problems: a metaanalysis. Journal of Advanced Nursing. 1999 Mar; 29(3): 62329. PMid:10210459. http://dx.doi.org/10.1046/j.1365-2 648.1999.00943.x

[2] Beck CT. State of the science on postpartum depression: what nurse researchers have contributed - part 1. American Journal of Maternal/Child Nursing. 2008 Mar-Apr; 33(2): 12126. PMid:18327112. http://dx.doi.org/10.1097/01. NMC.00 00313421.97236.cf

[3] Gavin N, Gaynes B, Lohr K, et al. Perinatal depression: a systematic review of prevalence and incidence. Obstetrics \& Gynecology. 2005 Nov; 106(5): 1071-83. PMid:16260528. http://dx.doi.o $\mathrm{rg} / 10.1097 / 01$. AOG.0000183597.31630.db

[4] Caramlau I, Barlow J, Sembi S, et al. Mums 4 Mums: structured telephone peer support for women experiencing postnatal depression. Pilot and exploratory RCT of its clinical and cost effectiveness. Trials. 2011 Mar; 12: 88. PMid:21439042. http://dx.doi .org/10.1186/1745-6215-12-88

[5] Dennis CL. The effect of peer support on postpartum depression: a pilot randomized controlled trial. The Canadian Journal of Psychiatry. 2003 Mar; 48(2): 115-124. PMid:12655910.

[6] Harris GE, Larsen D. HIV peer counseling and the development of hope: perspectives from peer counselors and peer counseling recipients. AIDS Patient Care and STDs. 2007 Nov; 21(11): 843859. PMid:18240894. http://dx.doi.org/10.1089/apc.200 6.0207

[7] Sherman BR, Sanders LM, Yearde J. Role-modeling healthy behavior: peer counseling for pregnant and postpartum women in recovery. Women's Health Issues. 1998 Jul-Aug; 8(4): 230-8. http: //dx.doi.org/10.1016/S1049-3867 (98)00013-9

[8] Hibbard MR, Cantor J, Charatz H, et al. Peer support in the community: initial findings of a mentoring program for individuals with traumatic brain injury and their families. Journal of Head Trauma Rehabilitation. 2002 Mar; 17(2): 112-31. http://dx.doi.org/1 0.1097/00001199-200204000-00004

[9] Murphy CA, Cupples ME, Percy A, et al. Peer-mentoring for firsttime mothers from socio-economic disadvantage: a qualitative study within a randomized controlled trial. BMC Health Services Research. 2008; 8: 46. http://dx.doi.org/10.1186/1472-696 3-8-46

[10] McInnes RJ, Stone DH. The process of implementing a communitybased peer breast feeding support programme: the Glasgow experience. Midwifery. 2001 Mar; 17(1): 65-73. PMid:11207106. http://dx.doi.org/10.1054/midw.2000.0236

[11] Johnson Z, Howell F, Molloy B. Community mothers' programme: randomized controlled trial of non-professional intervention in parenting. British Medical Journal. 1993 May; 306: 1449-
52. PMid:8518642. http://dx.doi.org/10.1136/bmj.306.6 890.1449

[12] Montgomery P, Mossey S, Adams S, et al. Stories of women involved in a postpartum depression peer support group. International Journal of Mental Health Nursing. 2012 Dec; 21(6): 52432. PMid:22738350. http://dx.doi.org/10.1111/j.1447-0 349.2012.00828. $\mathrm{x}$

[13] Fogarty B, Kingswell S. Pals in pregnancy: a luxury or a lifeline? British Journal of Midwifery. 2002 Sep; 10(9): 554-559. http://dx.doi.org/10.12968/bjom.2002.10.9.10610

[14] Doucet S, Letourneau N, Blackmore ER. Support needs of mothers who experience postpartum psychosis and their partners. Journal of Obstetric, Gynecologic and Neonatal Nursing. 2012 Mar; 41(2): 236-245. PMid:22375839. http://dx.doi.org/10.1111 $/ j .1552-6909.2011 .01329 . x$

[15] Letourneau N, Duffett-Leger L, Stewart M, et al. Canadian mothers' perceived support needs during postpartum depression. Journal of Obstetric, Gynecologic and Neonatal Nursing. 2007 Sep-Oct; 36(5): 441-9. PMid:17880314. http://dx.doi.org/10.1111/j $.1552-6909.2007 .00174 . \mathrm{x}$

[16] Dennis CL, Chung L. Postpartum depression help-seeking barriers and maternal treatment preferences: a qualitative systematic review. Birth. 2006 Dec; 33(4): 323-31. PMid:17150072. http: //dx.doi.org/10.1111/j.1523-536X.2006.00130.x

[17] Gjesfjeld CD, Weaver A, Schommer K. Rural women's transitions to motherhood: understanding social support in a rural community. Journal of Family Social Work. 2012 Oct; 15(5): 435-48. http://dx.doi.org/10.1080/10522158.2012.719182

[18] Leahy-Warren P, McCarthy G, Corcoran P. First-time mothers: social support, maternal parental self-efficacy and postnatal depression. Journal of Clinical Nursing. 2012 Feb; 21(3-4): 38897. PMid:21435059. http://dx.doi.org/10.1111/j.1365-2 702.2011.03701.x

[19] Negron R, Martin A, Almog M, et al. Social support during the postpartum period: mothers' views on needs, expectations, and mobilization of support. Maternal Child Health Journal. 2013 May; 17(4): 616-23. PMid:22581378. http://dx.doi.org/10.1007/s1099 5-012-1037-4

[20] Letourneau N, Stewart M, Dennis CL, et al. Effect of home-based peer support on maternal-infant interactions among women with postpartum depression: a randomized, controlled trial. International Journal of Mental Health Nursing. 2011 Oct; 20(5): 34557. PMid:21385294. http://dx.doi.org/10.1111/j.1447-0 $349.2010 .00736 . x$

[21] Giorgi A. The theory, practice and evaluation of the phenomenological method as a qualitative research procedure. Journal of Phenomenological Psychology. 1997; 28(2): 235-60. http://dx.doi . org/10.1163/156916297X00103 
[22] Starks H, Trinidad SB. Choose your method: a comparison of phenomenology, discourse analysis, and grounded theory. Qualitative Health Research. 2007 Dec; 17(10): 1372-80. PMid:18000076. http://dx.doi.org/10.1177/1049732307307031

[23] Yegdich T. In the name of Husserl: nursing in pursuit of the things-in-themselves. Nursing Inquiry. 2000 Mar; 7(1): 2940. PMid:11022533. http://dx.doi.org/10.1046/j.1440-1 $800.2000 .00050 . \mathrm{x}$

[24] Vivilaki V, Johnson M. Research philosophy and Socrates: rediscovering the birth of phenomenology. Nurse Researcher. 2008; 16(1): 84-92. PMid:19025108. http://dx.doi.org/10.7748/n r2008.10.16.1.84.c6755

[25] Giorgi, A. One type of analysis of descriptive data: procedures involved in following a scientific phenomenological method. Meth- ods: A Journal for Human Science. 1989; 1: 39-61.

[26] Scrandis DA. Normalizing postpartum depressive symptoms with social support. Journal of the American Psychiatric Nurses Association. 2005 Aug; 11(4): 223-30. http://dx.doi.org/10.1177/1 078390305280940

[27] Barnes J, Senior R, Macpherson K. The utility of volunteer homevisiting support to prevent maternal depression in the first year of life. Child: care health and development. 2009 Nov; 35(6): 80716. PMid:19719770. http://dx.doi.org/10.1111/j.1365-2 214.2009.01007.x

[28] Dennis CL, Hodnett E, Reisman HM, et al. Effect of peer support on prevention of postnatal depression among high risk women: multisite randomised controlled trial. British Medical Journal. 2009 Jan; 338: a3064. http://dx.doi.org/10.1136/bmj . a3064 